\title{
THE RICE PLANTING WINDOW IN THE PHILIPPINES: AN ANALYSIS USING MULTI-TEMPORAL SAR IMAGERY
}

\author{
M.A. Gutierrez ${ }^{1}$, N.M. Paguirigan ${ }^{1}$, J. Raviz ${ }^{1}$, M.R. Mabalay ${ }^{2}$, E. Alosnos ${ }^{2}$, L. Villano ${ }^{1}$, S. Asilo ${ }^{2}$, A. Arocena, Jr. ${ }^{2}$, \\ J. Maloom ${ }^{2}$, A. Laborte ${ }^{1}$ \\ ${ }^{1}$ International Rice Research Institute (IRRI), Los Baños, Laguna, Philippines - (m.reyes@irri.org, n.paguirigan@irri.org, \\ j.raviz@irri.org, 1.villano@irri.org, a.g.laborte@irri.org) \\ ${ }^{2}$ Philippine Rice Research Institute (PhilRice), Science City of Muñoz, Nueva Ecija, Philippines - \\ (mro.mabalay@philrice.gov.ph, ed.alosnos@philrice.gov.ph, sl.asilo@philrice.gov.ph, ac.arocenajr@philrice.gov.ph,
} im.maloom@philrice.gov.ph)

Commission IV

KEY WORDS: Crop calendar, planting duration, Rice, SAR, Sentinel-1, Philippines

\begin{abstract}
:
Knowing where and when rice is grown is essential for planning and decision-making in relation to food security, as well as in research wherein crop area and calendar are important inputs in crop production simulations, assessment of biotic and abiotic stresses, and analysis of the effect of climate change on crop production, among others. Remote sensing allows for efficient mapping and characterization of rice areas. In this study, we derived the rice planting window in all rice growing regions in the Philippines from 2016 to 2018 using multi-temporal Synthetic Aperture Radar (SAR), specifically TerraSAR-X and Sentinel-1. Using a rulebased method, rice area and Start of Season $(\mathrm{SoS})$ were mapped based on the unique backscatter behaviour of rice corresponding to the initial deliberate agronomic flooding followed by rapid biomass increase. We defined the planting window per year and semester as the $15^{\text {th }}$ and $85^{\text {th }}$ percentile and the peak of planting as the dominant planting date. The accuracy of the rice map was $93 \%$ and the SoS was strongly correlated with the actual planting dates reported by farmers $\left(\mathrm{R}^{2}=0.71\right)$ based on 482 ground observations in the Philippines in 2018 Semester 1. From this analysis, the planting window in the Philippines for the Semester 2 (wet season) is April-August (peak in June-July), and for Semester 1 (dry season) is September-February (peak in NovemberDecember) with large differences across regions. In majority of the regions, the planting window spans more than 100 days, which can have implications on incidence of pests and diseases.
\end{abstract}

\section{INTRODUCTION}

Rice remains the top agricultural commodity in the Philippines accounting for $93 \%$ of household consumption in 2015/2016 (PSA, 2017). The Philippines ranked $5^{\text {th }}$ among the largest rice consumers worldwide with 13.7 million metric tons of milled rice in 2018/2019 (Statista, 2019). The importance of rice in the country is evident and knowing where and when it is grown is essential for planning and decision-making in relation to food security, as well as in research wherein crop area and calendar are important inputs in crop production simulations, assessment of biotic and abiotic stresses, and analysis of the effect of climate change on crop production, among others.

Recent studies show that characteristics of crops such as the start of season (SoS), phenological stages, and even standing water beneath vegetation can be detected using multi-temporal Synthetic Aperture Radar (SAR) (Martinis, Rieke, 2015; Torbick et al., 2017; Bargiel, 2017). In comparison to optical sensors, SAR is independent of sun illumination and allows continuous imaging day and night amidst all atmospheric conditions (Le Toan, 2007). Furthermore, spaceborne SAR can accommodate wider area coverage at a higher resolution (Qiu et al., 2013). Hence, mapping of rice areas and detection of crop planting dates using SAR is a time efficient and cost effective means of obtaining up-to-date information (More et al., 2016).

Rice has a unique backscatter signature which is mainly influenced by its method of planting. Prior to sowing, farmers maintain a certain water depth on paddy fields to suppress weeds and pests. It is then followed by a significant increase in biomass until the heading stage wherein vegetation growth starts to decline. This makes rice unique compared to other agricultural crops and consequently it also allows a distinctive pattern from satellite signals thus making SAR sensors are reliable and powerful for rice crop characterization (Nguyen, Phung, 2012).

This study aims to define the rice planting window in all rice growing regions in the Philippines. We used multi-temporal SAR data from TerraSAR-X (TSX) in 2016 and Sentinel-1A/B (S1A/B) from 2016-2018. The information derived from this study can help in the proper timing and delivery of production inputs, and support the targeting of programs and incentives to minimize planting asynchrony and recommendations for adjustment of the cropping calendar to cope with the threats of changing climatic conditions (Imran et al., 2018). This can also provide information that can be used by decision makers in creating policies to mitigate deficits in rice availability and improve national production and yield (Laborte et al., 2017).

\section{STUDY AREA}

The study area covers all the rice growing regions of the Philippines (Figure 1). The Philippines has a total land area of 29.8 million ha and total rice area harvested in the country was 4.8 million hectares in 2018 (PSA, 2018). The country has four climatic types based on rainfall distribution, Type I: two pronounced seasons with the dry season from November to April and the wet for the rest of the year (Central Luzon, Western Visayas); Type II: no dry period, but with highest rains from November to January (Eastern Luzon, Eastern Visayas, and North-eastern Mindanao); Type III: dry from November to February and wet the rest of the year (Central Visayas, Western Bicol, Northern Mindanao), and Type IV: rainfall is more or less 
evenly distributed throughout the year (Central Mindanao) (GRiSP, 2013). Due to these diverse climatic conditions in the country, planting of rice varies from one region to another and also results in a wider planting window in some regions.

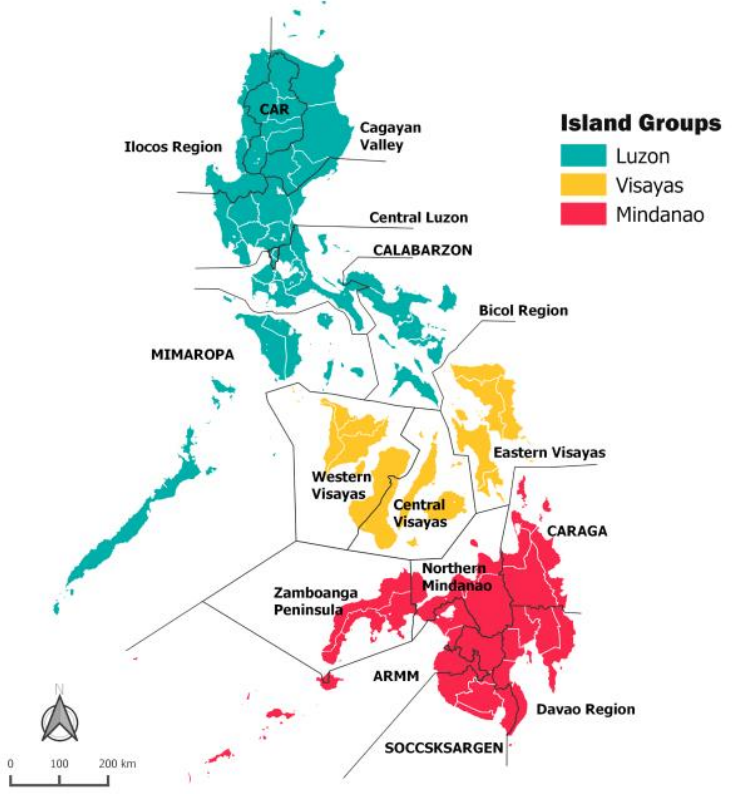

Figure 1. Island groups and regions in the Philippines.

\section{DATA AND METHODS}

\subsection{Data}

3.1.1 Satellite data: We used TSX (2016) and Sentinel-1A/B (2016-18) images to characterize rice area and seasonality (Table 1). The multi-temporal TSX were obtained from InfoTerra $\mathrm{GmbH}$ in $\mathrm{HH}$ polarizations with consistent incidence angles (39 to 48 degrees) for every multi-temporal stack in all locations. TSX carries a high frequency X-band HH SAR sensor with a $3.11-\mathrm{cm}$ wavelength and a repeat cycle of 11 days. (Airbus Defense and Space, 2015). Sentinel-1, on the other hand, has two satellites Sentinel-1A (S-1A) launched in April 2014 and Sentinel-1B (S-1B), launched in April 2016. S-1A and S-1B each acquires images every 12 days. The combination of the two provides a shorter repeat cycle, making satellite images available up to 6 days in some areas. Both satellites carry a C-band sensor that acquires images with $20 \mathrm{~m}$ resolution and available at no cost (ESA, 2019; Copernicus, 2019). For this study, we used the Interferometric Wide Swath in VV and VH polarizations.

\begin{tabular}{|c|c|c|}
\hline Feature & $\begin{array}{l}\text { Sentinel-1 } \\
(\text { S-1A/B) }\end{array}$ & TSX \\
\hline Type of sensor & Active (radar) & Active (radar) \\
\hline Product (mode) & $\begin{array}{l}\text { Interferometric Wide } \\
\text { Swath }\end{array}$ & ScanSAR mode \\
\hline Band & C-band & X-band \\
\hline Polarization & $\mathrm{VV}, \mathrm{VV}+\mathrm{VH}$ & $\mathrm{HH}, \mathrm{VV}$ \\
\hline $\begin{array}{l}\text { Spatial resolution } \\
\text { (m) }\end{array}$ & 20 & 18.5 \\
\hline Swath width $(\mathrm{km})$ & $250 \times 250$ & $100 \times 150$ \\
\hline Repeat cycle (days) & 12 , up to 6 & 11 \\
\hline Image availability & Free & Commercial \\
\hline Year of launch & 2014 (S-1A), 2016 (S-1B) & 2007 \\
\hline Source & $\begin{array}{c}\text { European Space Agency } \\
\text { (ESA) }\end{array}$ & $\begin{array}{l}\text { Infoterra Gmbh, } \\
\text { Germany }\end{array}$ \\
\hline
\end{tabular}

3.1.2 Ground data: Observations from monitoring fields were collected to assess the accuracy of the SoS data. A total of 482 ground observations in 2018 Semester 1 were used for the assessment. Actual planting/ sowing information of rice were gathered through farmer interviews.

3.1.3 Administrative boundaries: The Philippine administrative boundaries (island groups, regions, provinces) used in this study for grouping and mapping results was obtained from the Philippine Statistics Authority (PSA).

3.1.4 Weather data: In this study, we also analysed the shift in planting window due to drought in 2016. Historical daily rainfall data (1986 to 2016) from two weather stations in Mindanao (Cotabato and Malaybalay) and dryspell/drought report (January to May 2016) from the Philippine Atmospheric, Geophysical and Astronomical Services Administration (PAGASA) were used to validate the drought situation in 2016.

\subsection{Methodology}

3.2.1 Generation of start of season (SoS) maps: The multitemporal high resolution images from TSX and S-1A/B were preprocessed using MAPscape-RICE® (Nelson et al., 2014; Raviz et al., 2018). The pre-processing was performed to convert the multi-temporal SAR data into terrain-geocoded backscatter $\left(\sigma^{\circ}\right)$ values. Specific threshold parameters were set to detect both rice area and start of season dates. Start of season was detected based on the value of reliability coefficient (RC) computed after satisfying the following conditions: (1) SAR backscatter value (VV and VH polarization), (2) increase in backscatter observed after the SoS, (3) correspondence of SoS date in VV and VH polarizations, and (4) value of local incidence angle (LIA) in overlapping areas. The $\mathrm{RC}$ was computed by multiplying its own weight factor to the aggregated contribution of each parameter. It is necessary that the setting of parameters was guided by user's expertise, expert local knowledge, and other relevant information that would be useful in the setting of the parameter values (Raviz et al., 2018). Accuracy assessment was performed using field data (Nelson et al., 2014; Raviz et al., 2018; IRRI, PhilRice, 2018). Table 2 lists the SAR imagery and acquisition dates used in the derivation of the SoS dates.

\begin{tabular}{ll|cll}
\hline Satellite & $\begin{array}{c}\text { Year, } \\
\text { Semester }\end{array}$ & $\begin{array}{c}\text { Number of } \\
\text { acquisition } \\
\text { dates } \\
\text { average) }\end{array}$ & First & Last \\
\hline TSX & 2016 Sem1 & 10 & Sep 25, 2015 & Feb 21, 2016 \\
& 2016 Sem2 & 8 & May 13, & Sep 17, 2016 \\
& 2017 Sem1 & 6 & Oct 30, 2016 & Jan 10, 2017 \\
\hline S-1A & 2016 Sem1 & 12 & Oct 2, 2015 & Mar 30, 2016 \\
& 2016 Sem2 & 15 & Mar 8, 2016 & Sep 21, 2016 \\
& 2017 Sem1 & 16 & Sep 16, 2016 & Mar 30, 2017 \\
& 2017 Sem2 & 17 & Mar 18, 2017 & Sep 30, 2017 \\
& 2018 Sem1 & 16 & Sep 16, 2017 & Mar 29, 2018 \\
& 2018 Sem2 & 16 & Mar 17, 2018 & Sep 30, 2018 \\
\hline S-1B & 2018 Sem1 & 16 & Sep 18, 2017 & Mar 29, 2018 \\
& 2018 Sem2 & 16 & Mar 17, 2018 & Sep 25, 2018 \\
\hline
\end{tabular}

Table 2. SAR images used for each year and semester.

Generally, rice in the Philippines is cultivated during two main cropping seasons, namely the wet and dry. To avoid confusion with the seasonal timeline, we followed the calendar set by the Department of Agriculture (DA) which is based on the semester when rice is harvested, (1) Semester 1 (dry season) refers to rice planted from September 16 to March 15; and (2) Semester 2 (wet season) refers to rice planted from March 16 to September 15. 
3.2.2 Accuracy assessment of SoS dates: We used 482 ground observations collected during 2018 Semester 1 to assess the accuracy of the derived SoS dates based on linear correlation analysis. The Root Mean Square Error (RMSE) was also computed to assess the difference between the estimated and actual values.

3.2.3 Planting window: We performed three main steps to generate the planting window in the Philippines: (1) reclassification of SoS dates from Julian dates (e.g. 1 Jan 2016) to day of year (DOY), (2) calculation of number of pixels per DOY, and (3) identification of start, peak, and end of planting per semester (Figure 2). We used the ArcGIS software for the first and second steps of the process.

Reclassification of SoS planting dates: We reclassified all planting dates to DOY to have consistent unique raster values for all SoS maps from 2016 to 2018. First, we prepared the reclass tables per year and semester. We extracted the ID and planting dates from each SoS map and linked the corresponding DOY value for each planting date (e.g. 1 January = 1). Because Semester 1 covers two year periods, we used the values 1 to 365 for the DOY in the first year and added 365 in the DOY value for the same month and day in the second year (e.g. Jan 1, 2016 = 1 and Jan $1,2017=366$ ). We changed the DOY values for the second year to maintain the order of the planting dates per year and semester. Next, we used the country-level administrative map as an input mask to make sure that all reclassified maps will have the same extent.

Identification of yearly planting window (by semester): Using the reclassified SoS map and the regional map, we calculated the number of pixels per DOY, province and region. We grouped the DOY into first half and second half of the month (e.g. DOY 1 to $15=$ "Jan 1-15", DOY 349 to $365=$ "Dec 16-31", DOY 366 to $380=$ "Jan 1-15").

We selected the $15^{\text {th }}$ and $85^{\text {th }}$ percentile of the calculated number of pixels to identify the start and end of planting per region, respectively. We used these instead of the earliest and latest dates per administrative unit (region and province) to remove outliers. As for the peak of planting, we selected the period (DOY group) with the most total number of pixels per administrative unit. Having the most number of pixels means that most of the farmers planted rice in their fields within that period.

Identification of final planting window using the 3-year data (by semester): To identify the planting period by region, we selected the minimum (earliest) start of planting and maximum (latest) end of planting across years to identify the final start and end of planting per administrative unit. We used the median instead of the mean peak of planting across years to better reflect the general planting situation across years. The median will also reduce the effect of very late peak planting occurring in one of the three years. We used data from 2016 to 2018 except for Mindanao wherein we excluded 2016 due to reported drought in 2016.

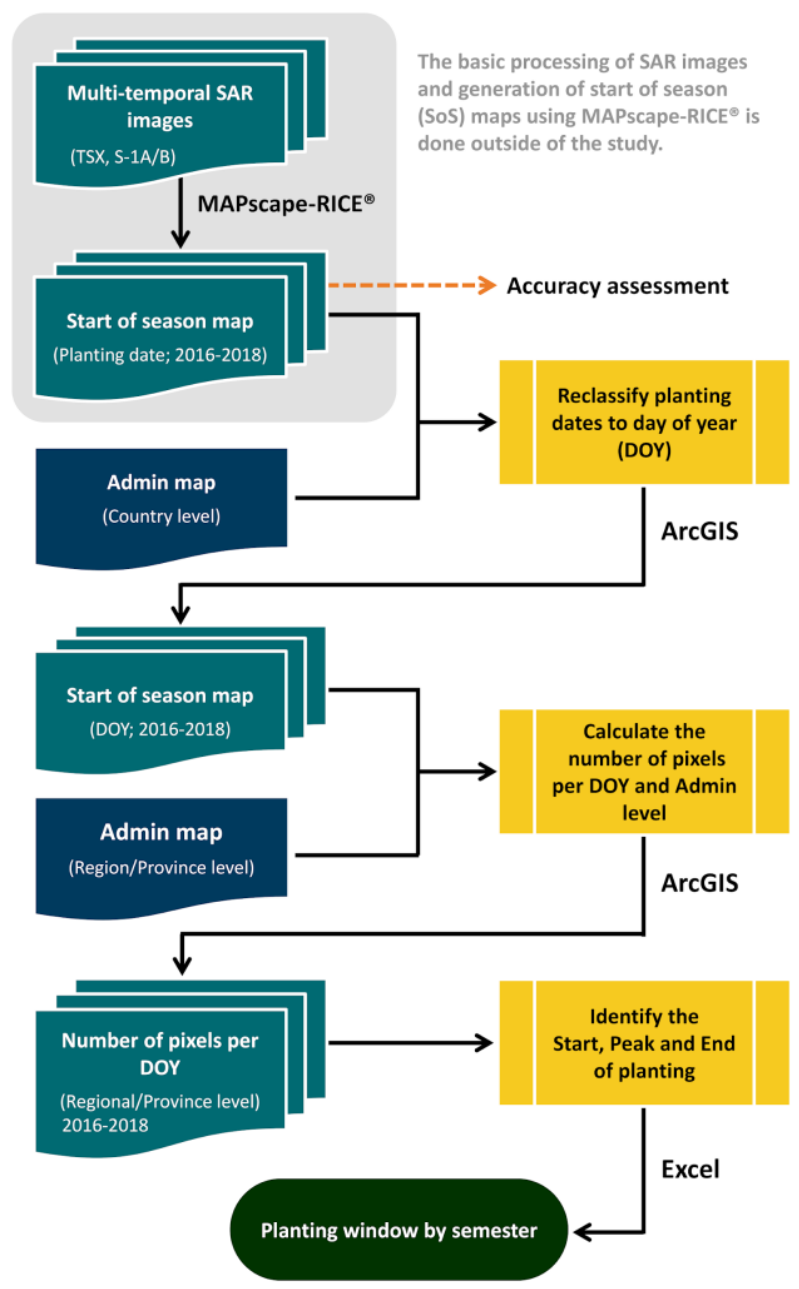

Figure 2. Planting window process flow used in this study.

3.2.4 Planting duration: We defined the planting duration as the number of days between the start and end of planting. Figure 3 shows four examples on how the planting duration was computed depending on whether the start and end of planting falls on the $1^{\text {st }}$ or $2^{\text {nd }}$ half of the month.

\begin{tabular}{l|l}
\hline $\begin{array}{l}\text { Start: Sept 16-30 } \\
\text { End: Nov } 16-30\end{array}$ & $\begin{array}{l}\text { Start: Sept 1-15 } \\
\text { End: Nov } 16-30\end{array}$ \\
$\begin{array}{l}\text { Sept }=15 \text { days } \\
\text { October }=31 \text { days } \\
\text { November }=30 \text { days }\end{array}$ & $\begin{array}{l}\text { Sept }=30 \text { days } \\
\text { October }=31 \text { days } \\
\text { November }=30 \text { days }\end{array}$ \\
Planting duration: 76 days & Planting duration: 91 days \\
\hline $\begin{array}{l}\text { Start: } \text { Sept } 16-30 \\
\text { End: Nov } 1-15\end{array}$ & $\begin{array}{l}\text { Start: } \text { Sept } 1-15 \\
\text { End: } \text { Nov } 1-15\end{array}$ \\
Sept $=15$ days & Sept $=30$ days \\
October $=31$ days & October $=31$ days \\
November $=15$ days & November $=15$ days \\
Planting duration: 51 days & Planting duration: 76 days \\
\hline
\end{tabular}

Figure 3. Sample computation of planting duration 
3.2.5 Shift in planting window due to drought in 2016: The Food and Agriculture Organization of the United Nations (FAO) reported in March 2016 that $40 \%$ of the country was affected by drought (FAO, 2016). Most of the affected areas were in the Mindanao island group (ACAPS, 2016). Drought condition was observed from January to May of 2016. We compared the daily cumulative annual rainfall in 2016 against the long term mean from 1986 to 2016 at two selected weather stations in Mindanao to see the effect of drought on rainfall distribution. We used the generated provincial planting window by province in Mindanao to analyse the shift in the planting window as a result of the drought.

\section{RESULTS AND DISCUSSION}

\subsection{Derived SoS and accuracy assessment}

The SoS maps derived from multi-temporal SAR is shown in Appendix 1. There was a wide variation in the SoS detection across regions and province. In Semester 1 the peak of SoS was detected in November/December (Visayas and Mindanao) and December/January (Luzon) while the range started from September and the latest was March across years. In Semester 2, the SoS was detected from March to September with peak in June for 2016/2017, and July for 2018 (Visayas and Mindanao) and July for 2016/2018 (Luzon).

The SAR-derived SoS dates are strongly correlated with the actual crop establishment dates as reported by farmers $\left(\mathrm{R}^{2}=\right.$ 0.71 ) in selected rice fields in the Philippines for 2018 Semester 1 . The estimated and the actual values also exhibited an average deviation of 23 days which is equivalent to nearly two image acquisitions. A graphical illustration of the comparison between the estimated and actual dates is shown in Figure 4.

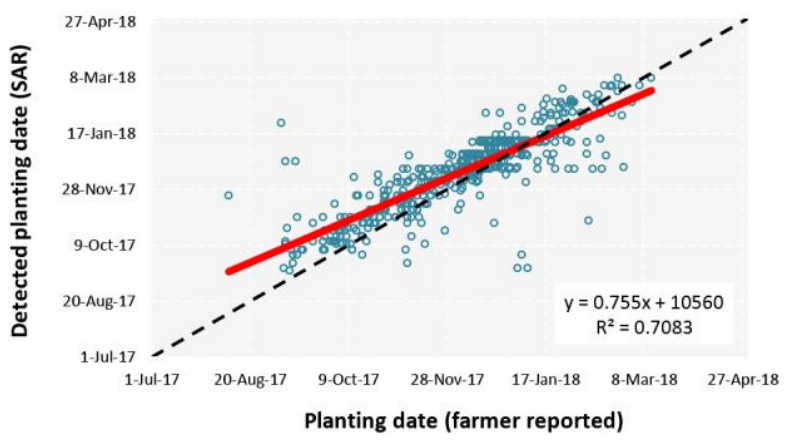

Figure 4. Comparison between the estimated SoS-derived dates from SAR and actual planting dates reported by farmers in selected rice fields in four provinces in the Philippines for 2018 Semester 1. One dot corresponds to one monitoring field.

\subsection{Planting window}

Majority of rice were planted during the months of November and December for Semester 1, whereas for Semester 2, the peak of planting was from June to July which coincides with the Southwest monsoon (Habagat). Figure 5 shows the peak of planting, presented bi-monthly, for both semesters at provincial level.

The provinces of Misamis Oriental, Basilan and Sulu, all in Mindanao, were among the provinces wherein peak of planting for Semester 1 was early (September). Meanwhile, most provinces in Luzon had their peak of planting later in the semester (January). For Semester 2, the earliest peak of planting was April for Surigao del Sur in Mindanao while latest peak of planting was observed in August in the provinces of Guimaras and Bohol in Visayas, and Camiguin in Mindanao.

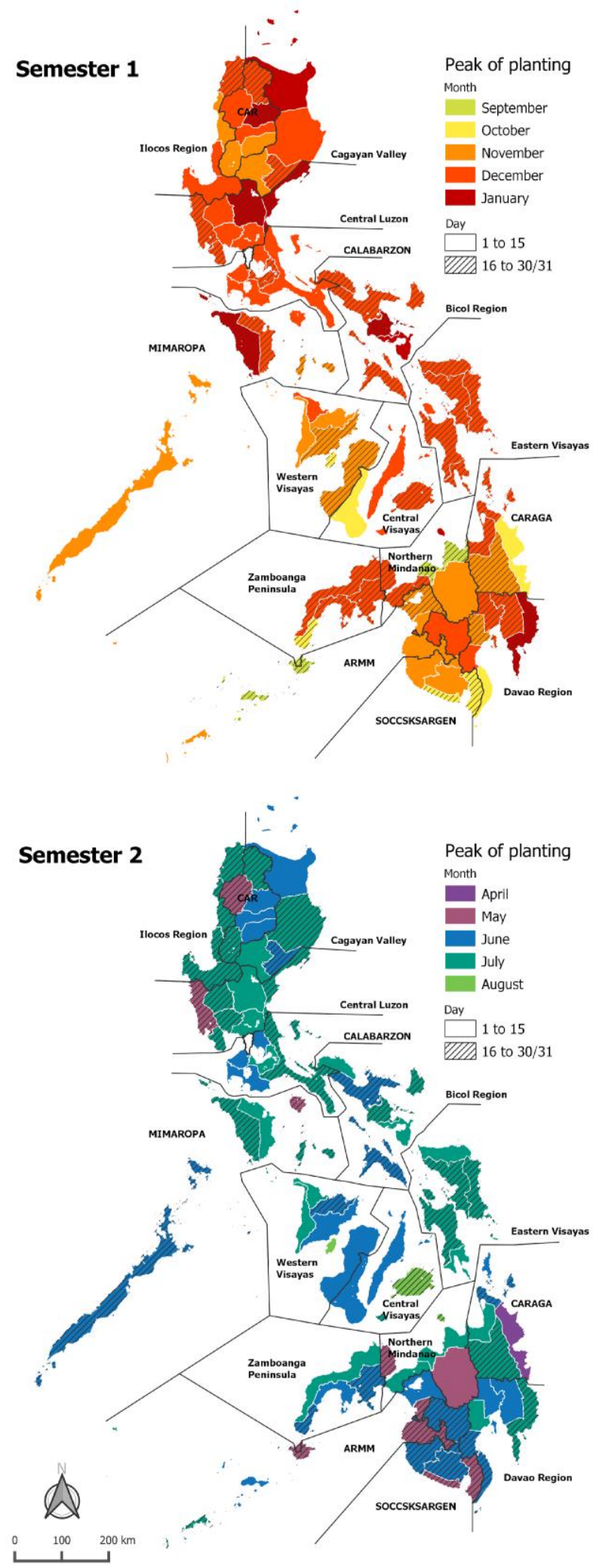

Figure 5. Peak of planting of rice by province and semester in the Philippines, 2016-2018.

The SAR-derived data used in the analysis has been carried out from 2016 to 2018 only. Shifts in planting calendar as a result of 
farmer's practices and climate change may be observed and analysed as more years of data become available.

\subsection{Planting duration}

Figure 6 shows the start, peak, and end of planting in months by semester at regional level from 2016 to 2018. In the study area, the planting window for Semester 2 ranged from April to August (peak in June-July), and for Semester 1 from September to February (peak in November-December) with significant variations from region to region. The regions with the earliest and latest start of planting detected by semester are shown in Table 3.

\begin{tabular}{lcccc}
\hline & \multicolumn{3}{c}{ Start of rice planting } \\
\cline { 2 - 4 } & \multicolumn{2}{c}{ Semester 1 } & \multicolumn{2}{c}{ Semester 2 } \\
\cline { 2 - 4 } Month & Earliest & Latest & Earliest & Latest \\
\cline { 2 - 4 } Region & September & November & April & June \\
& Zamboanga & Central Luzon, & ARMM & Eastern \\
& Peninsula, & MIMAROPA, & & Visayas, \\
& Northern & Eastern Visayas & & Northern \\
& Mindanao & & Mindanao, \\
& & & Davao, \\
& & & & CARAGA \\
\hline
\end{tabular}

Table 3. Regions with the earliest and latest start of rice planting by semester.

For Semesters 1 and 2, the longest planting duration were observed in CARAGA and ARMM (Mindanao) with 137 days or more than four months. In contrast, the shortest duration was observed in MIMAROPA (Luzon) and Davao (Mindanao) with 76 and 61 days for Semesters 1 and 2, respectively. Based on the provincial maps, the shortest planting duration was observed in Capiz in Visayas (Semester 1) with 60 days and Davao del Norte in Mindanao (Semester 1 and 2) with 45 days while the longest planting duration was observed in the majority of the provinces in Mindanao and Luzon for Semester 1 (Figure 7). Most of these provinces with longer planting duration in Semester 1 have Type II and Type IV climate wherein there is no distinct dry period and rainfall is distributed during the year. Longer planting duration may lead to asynchronous planting which in turn can lead to high incidence of pests and diseases.

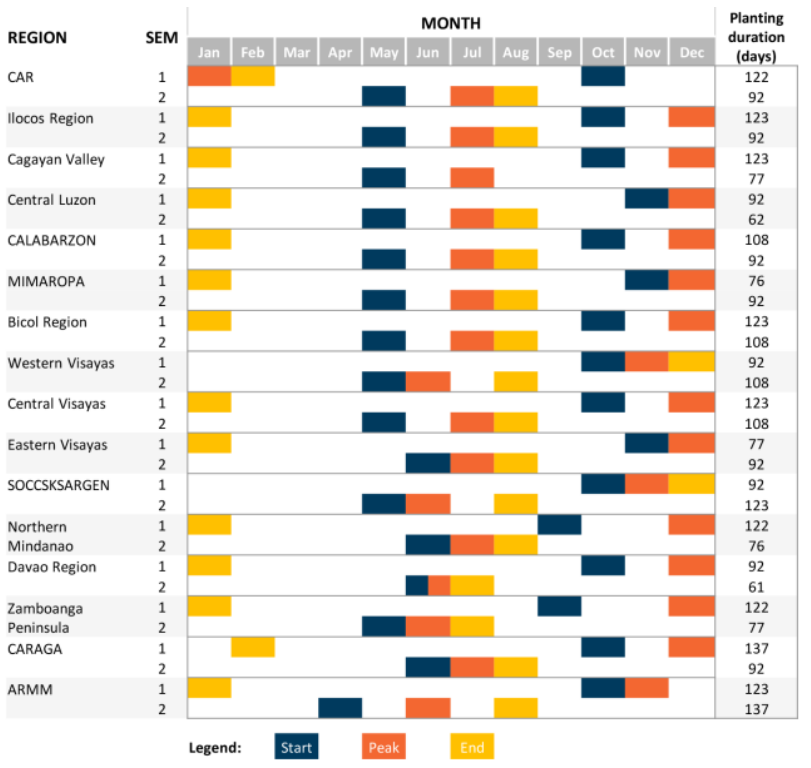

Figure 6. Start, peak and end of planting and duration of planting dates by semester and region in the Philippines, 2016-2018.
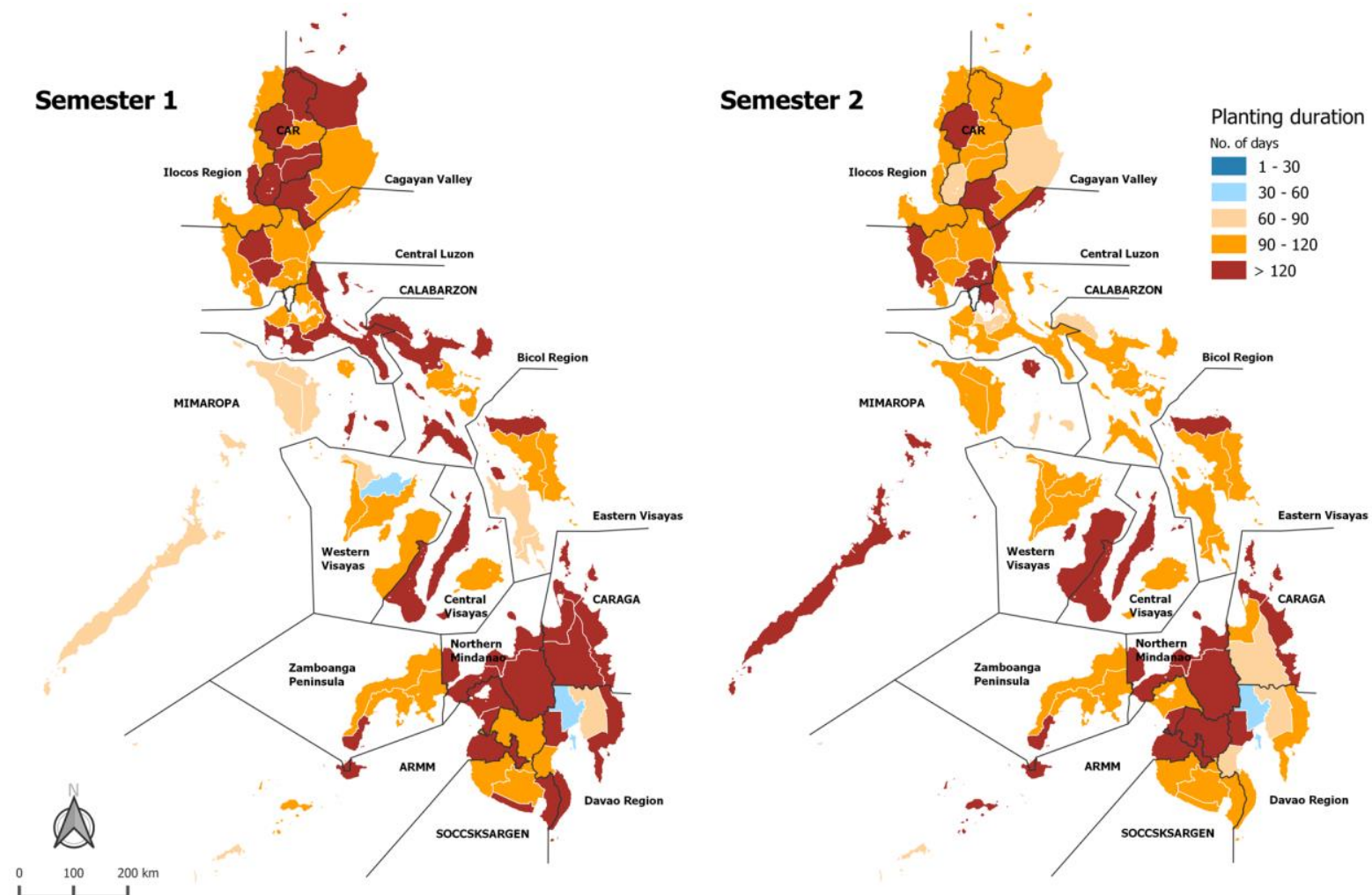

Figure 7. Duration of planting dates (in days) by semester and province in the Philippines, 2016-2018. 


\subsection{Shift in planting window due to drought in 2016}

In 2016, rice farming in some parts of the country, mostly in Mindanao, was affected due to drought. Based on the April 2016 assessment of PAGASA, 21 provinces were affected by drought and one was affected by dry spell in Mindanao. Some municipalities in the area were even declared under the state of calamity due to prolonged drought. The creeks dried up and the release of irrigation water was delayed, therefore farmers were forced to adjust their period of planting. The cumulative longterm (1986-2016) and daily rainfall data for 2016 from two weather stations in Mindanao (Cotabato and Malaybalay) show the below normal rainfall during the first five months in 2016 (Figure 8). No rice fields were detected to be planted from March to mid-May in 2016 (wherein drought was reported) and majority of planting started in the month of June (Figure 9). Under normal climatic conditions (2017 and 2018), some fields were already planted in April and May. This demonstrates how SAR can accurately detect the planting dates and shifts in the planting window due to extreme weather condition like drought.

\section{CONCLUSION}

The use of multi-temporal SAR-based sensors is one of the quick and effective ways of determining the planting dates of rice that could cover even the whole country. The high temporal resolution of the combined Sentinel-1 with update frequency of up to 6 days provides promising results and greater accuracy for the derived SoS maps. This study shows the wide variation in planting dates detected across the country and even within regions. Generally, the provinces of Mindanao start planting rice earlier compared to those in Luzon and Visayas. Moreover, the longest planting window was also observed in Mindanao particularly the ARMM and CARAGA regions. The information provided in this study has potential application in proper timing and delivery of agricultural input supplies, tracking the rice cultivation and estimating adjusted sowing, and targeting of programs for promoting optimal planting dates to increase yield and reduce planting asynchrony to reduce pest and disease problems. This analysis covers three years and six rice growing seasons from 2016 to 2018 and may be updated as more years of SAR-derived SoS data become available. A longer time series will allow for analysis of shifts in planting window due to changes in farmers' practices or climate change.
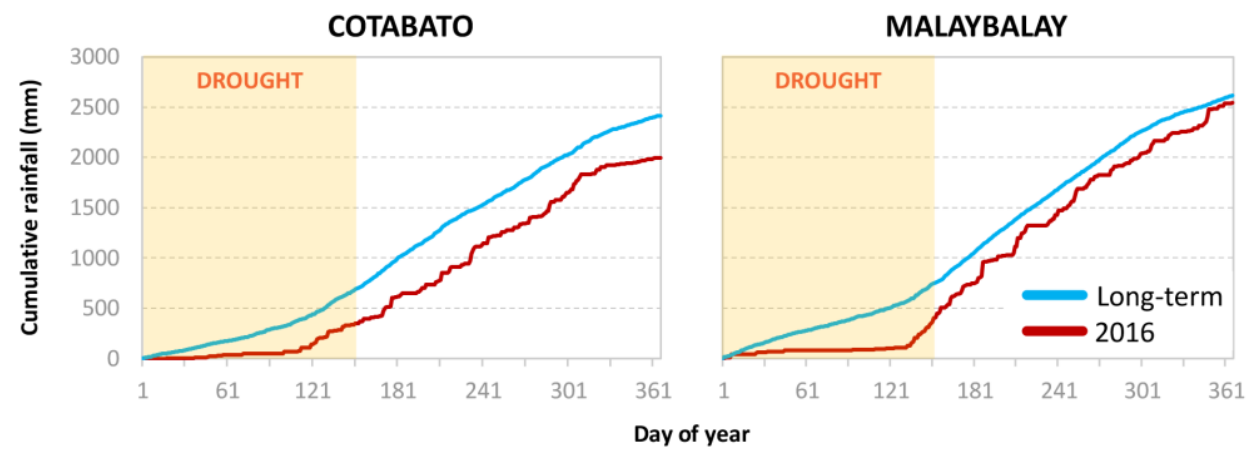

Figure 8. Comparison of 2016 and long-term (1986-2016) cumulative daily rainfall for two weather stations in Mindanao.

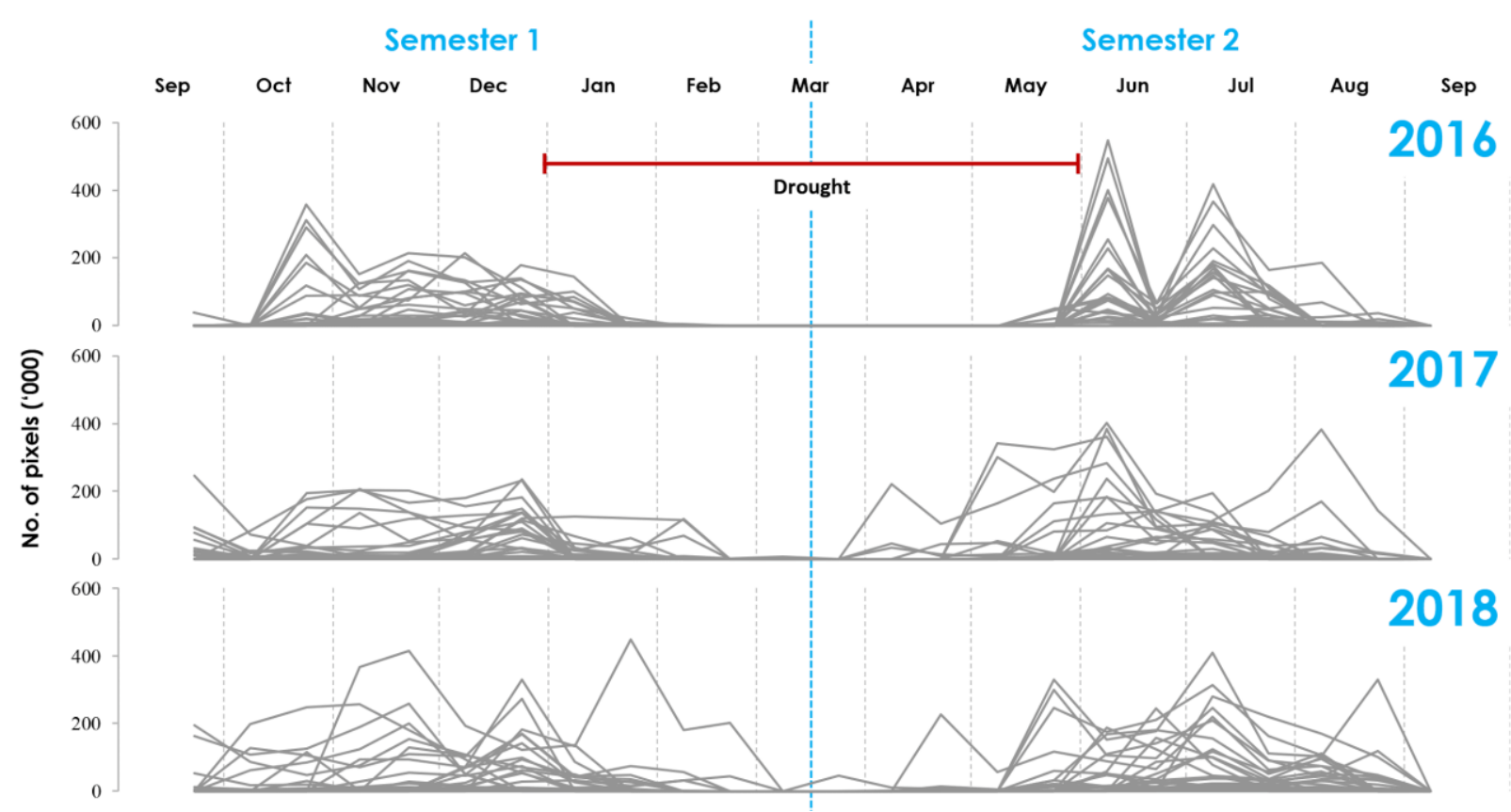

Figure 9. Drought duration (2016) and provincial rice planting window in Mindanao, 2016-2018. 


\section{ACKNOWLEDGEMENT}

The authors gratefully acknowledge the Philippine Rice Information System (PRISM) and Pest Risk Identification and Management (PRIME) projects, and project staff from IRRI, PhilRice and Department of Agriculture (DA) Regional Field Offices for the processed SAR imagery, rice and SoS maps, and ground observation data used in the analysis of this study. The PRISM and PRIME are projects funded by the DA National Rice Program through the Bureau of Agricultural Research (DABAR). SAR data were provided by the Copernicus Sentinel Data (2016-2018) from the European Space Agency (ESA) for Sentinel.

\section{REFERENCES}

ACAPS, 2016. ACAPS Briefing Note: Drought in the Philippines. https://reliefweb.int/sites/reliefweb.int/files/ resources/b-philippines-drought.pdf (27 August 2019).

Airbus Defence and Space, 2015. TerraSAR-X Image Product Guide. 2.1., 1-24. https://www.intelligenceairbusds.com/files/pmedia/public/r459_9_20171004_tsxxairbusds-ma-0009_tsx-productguide_i2.01.pdf $\quad(10 \quad$ August 2019).

Bargiel, D., 2017. A new method for crop classification combining time series of radar images and crop phenology information. Remote Sensing of Environment. 198, 369-383. doi.org/10.1016/j.rse.2017.06.022.

Copernicus, 2019. Copernicus Open Access Hub. https://scihub.copernicus.eu (29 August 2019).

ESA, 2019. ESA earth Online. https://earth.esa.int/web/guest/missions/esa-operational-eomissions/sentinel-1 (29 August 2019).

Food and Agriculture Organization of the United Nations (FAO), 2016. El Niño: Preparedness and Response Situation Report. https://reliefweb.int/sites/reliefweb.int/files/resources/ GlobalElNinoSitRep_March2016.pdf (27 August 2019).

GRiSP (Global Rice Science Partnership), 2013. Rice Almanac. 4th Edition, International Rice Research Institute, Los Baños, Laguna, Philippines.

Imran, M., Basit, I., Khan, M.R., Ahmad, S.R., 2018. Analyzing the Impact of Spatio-Temporal Climate Variations on the Rice Crop Calendar in Pakistan. Internationl Journal of Agricultural and Biosystems Engineering. $12 \quad$ (6),177-184. waset.org/Publication/10009155.

IRRI, PhilRice. PRISM Bulletin. El Niño Series. No. 4. April 10, 2016.

IRRI, PhilRice, 2018. PRISM Terminal Report. Unpublished.

Laborte, A., Gutierrez, M.A., Balanza, J.G., Saito, K., Zwart, S., Boschetti, M., Murty, M.V.R., Villano, L., Aunario, J.K., Reinke, R., Koo, J., Hijmans, R., Nelson, A., 2017. Rice Atlas, a spatial database of global rice calendars and production. Scientific Data, 4(170074). doi.org/10.1038/sdata.2017.74.

Le Toan, T., 2007. Introduction to SAR Remote Sensing. Lecture for Advance Training Course on Land Remote Sensing.
https://earth.esa.int/landtraining07/D1LA1-LeToan.pdf (29 August 2019).

Martinis, S., Rieke, C., 2015. Backscatter Analysis Using MultiTemporal and Multi-Frequency SAR Data in the Context of Flood Mapping at River Saale, Germany. Remote Sens. 7, 7732 7752. Doi.org/10.3390/rs70607732.

More, R.S., Manjunath, K.r., Jain, N.K., Panograhy, S., Parihar, J.S., 2016. Derivation of rice crop calendar and evaluation of crop phenometrics and latitudinal relationship for major south and south-east Asian countries: A remote sensing approach. Computers and Electronics in Agriculture. 127, 336-350. doi,org/10.1016/j.compag.2016.06.026.

Nelson, A., Setiyono, T., Rala, A.B., Quicho, E.D., Raviz, J.V., Abonete, P.J., Maunahan, A.A., Garcia, C.A., Bhatti, H.Z., Villano, L.S., Thongbai, P., Holecz, F., Barbieri, M., Collivignarelli, C., Gatti, L., Quilang, E.J.P., Mabalay, M.R., Mabalot, P.E., Barroga, M.I., Bacong, A.P., Detoito, N.T., Berja, G.B., Varquez, F., Wahyunto., Kuntjoro, D., Murdiyati, S.R., Pazhanivelan, S., Kanna, p., Mary, P.C.N., Subramanian, E., Rakwatin, P., Intrman, A., Setapayak, T., Lertna, S., Minh, V.Q., Tuan, V.Q., Duong, T.H., Quyen, N.H., Kham, D.V., Hin, S., Veana, T., Yadav, M., Chin, C., Nihn, N.H., 2014. Toward an operational SAR-based rice monitoring system in Asia: Examples from 13 Demonstration Sites across Asia in the RIICE project. Remote Sens. 6, 10773-10812. doi.org/10.3390/rs61110773.

Nguyen, L.D., Phung, H.P., 2012. Rice Crop Monitoring in the Mekong Delta, Vietnam using Terrasar-X and ENVISAt-ASAR Radar data. International Symposium on Geoinformatics for Spatial Infrastructure Development in Earth and Allied Sciences. http://gisws.media.osaka-

cu.ac.jp/gisideas12/viewpaper.php?id=442 (10 August 2019).

Philippine Atmospheric, Geophysical and Astronomical Services Administration (PAGASA), 2016. Drought/dry Spell Assessment (May 2015-2016).

https://pubfiles.pagasa.dost.gov.ph/climps/weathersit/DDSasses sment_2015-2016.pdf (29 August 2019).

Philippine Statistics Authority (PSA), 2017. Consumption of Agricultural Commodities in the Philippines. Volume 1. PSA, Quezon City, Philippines. https://psa.gov.ph/sites/default/files/ 2015-2016\%20CSAC\%20Vol1.pdf (10 July 2019).

Philippine Statistics Authority (PSA), 2018. openstat.psa.gov.ph (10 August 2019)

Qiu, X., Ding, C., Hu, D., 2013. Bistatic SAR Data Processing Algorithms. John Wiley \& Sons Singapore Pte. Ltd., Singapore.

Raviz, J., Laborte, A., Gatti, L., Mabalay, R., Holecz, F., 2018. Detection of start of season dates of rice crop using SAR and optical imagery, Central Luzon, Philippines. In: Proceedings Asian Conference on Remote Sensing 2018: Remote Sensing Enabling Prosperity; 2018 October 15-19; Kuala Lumpur, Malaysia.

Statista, 2019. https://www.statista.com/statistics/255971/ topcountries-based-on-rice-consumption-2012-2013/

Torbick, N., Chowhury, D., Salas, W., Qi, Jiaguo., 2017. Monitoring Rice Agruicultur across Myanmar Using Time Series Sentinel-1 Assisted by Landsat-8 and PALSAR-2. Remote Sens. 9, 119, 1-22. doi.org/10.3390/rs9020119. 

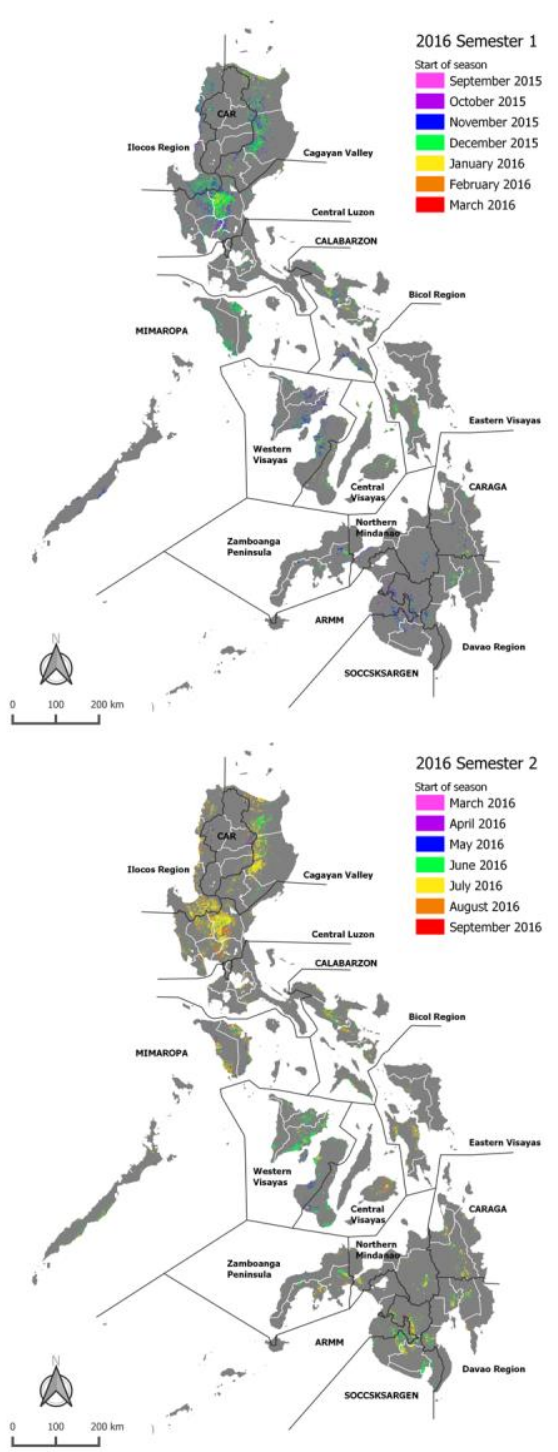

\section{APPENDIX}
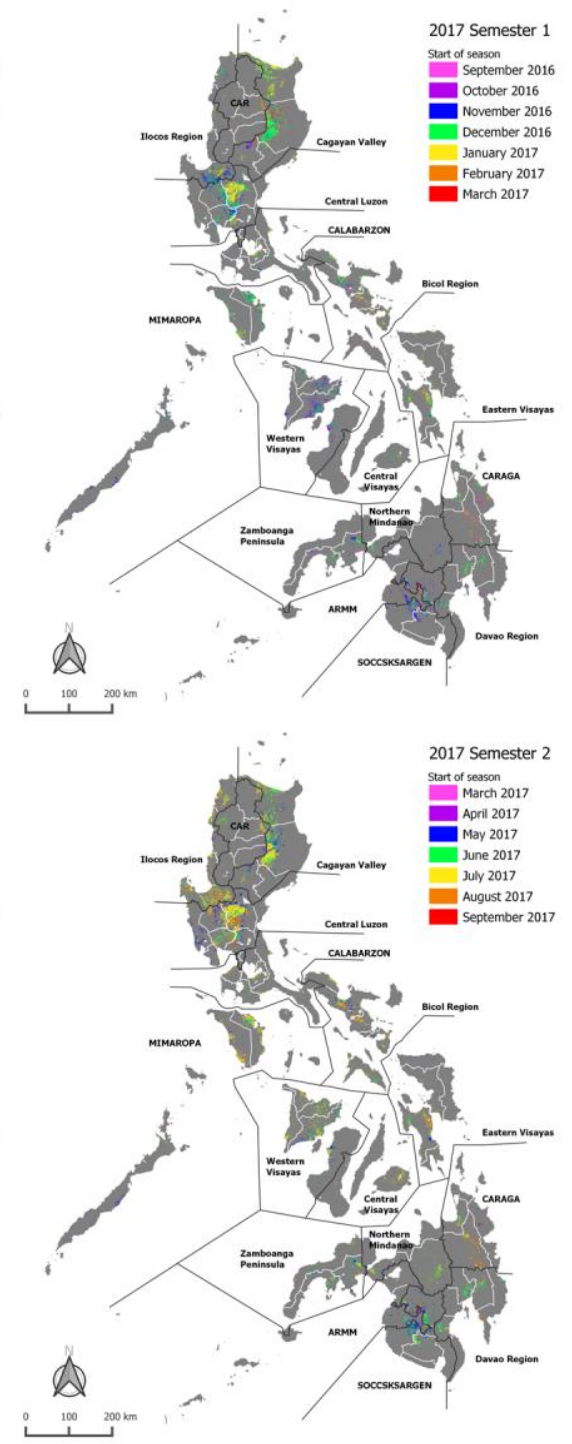
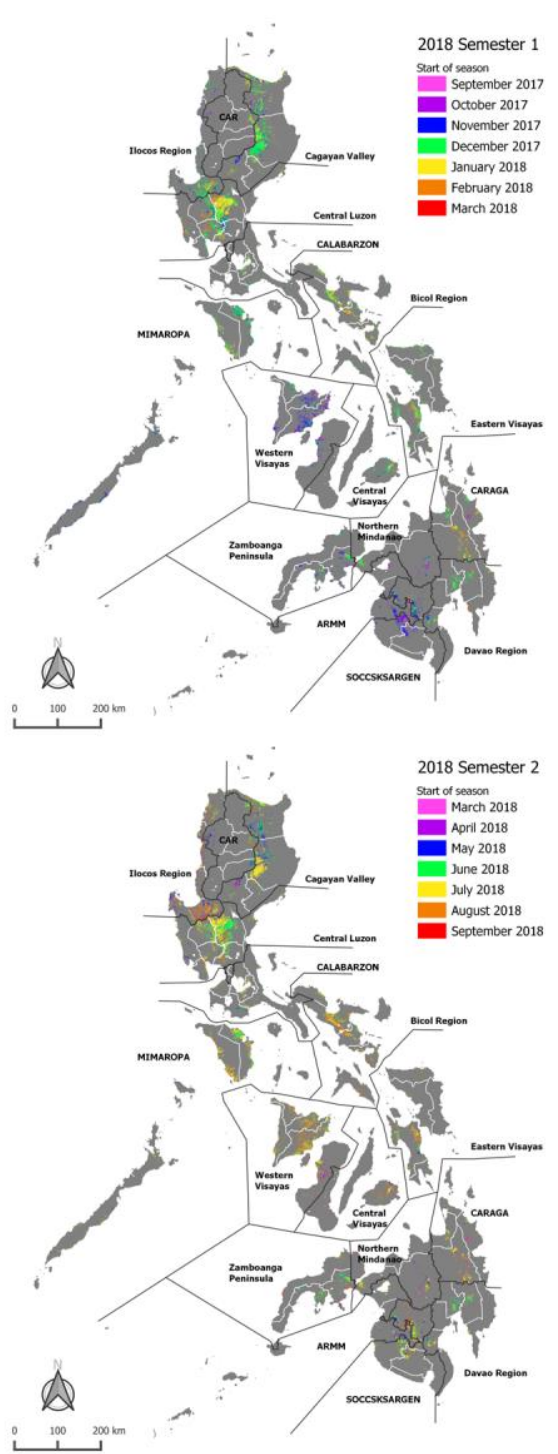

Appendix 1. Map of start of season (SoS) in the Philippines by semester, 2016-2018. 